\title{
PEDOT:PSS Nanofilms Fabricated by a Nonconventional Coating Method for Uses as Transparent Conducting Electrodes in Flexible Electrochromic Devices
}

\author{
Kanyanee Sanglee, ${ }^{1,2}$ Surawut Chuangchote, ${ }^{1,2}$ \\ Pipat Chaiwiwatworakul, ${ }^{1}$ and Pisist Kumnorkaew ${ }^{3}$ \\ ${ }^{1}$ The Joint Graduate School of Energy and Environment, Centre of Excellence on Energy Technology and Environment, \\ King Mongkut's University of Technology Thonburi (KMUTT), 126 Pracha Uthit Rd., Bangmod, Tungkru, Bangkok 10140, Thailand \\ ${ }^{2}$ Nanoscience and Nanotechnology Graduate Program, King Mongkut's University of Technology Thonburi (KMUTT), \\ 126 Pracha Uthit Rd., Bangmod, Tungkru, Bangkok 10140, Thailand \\ ${ }^{3}$ National Nanotechnology Center, National Science and Technology Development Agency, 111 Thailand Science Park, \\ Phahonyothin Rd., Khlong Nueng, Khlong Luang, Pathumthani 12120, Thailand
}

Correspondence should be addressed to Surawut Chuangchote; surawut.chu@kmutt.ac.th

Received 23 September 2016; Accepted 16 November 2016; Published 22 January 2017

Academic Editor: Shiren Wang

Copyright (C) 2017 Kanyanee Sanglee et al. This is an open access article distributed under the Creative Commons Attribution License, which permits unrestricted use, distribution, and reproduction in any medium, provided the original work is properly cited.

Nanofilms of a polymer mixer of two ionomers, poly 3,4-ethylenedioxythiophene:poly(styrene sulfonic acid) (PEDOT:PSS), were used as conducting materials to develop transparent conducting electrodes. It was firstly found that convective deposition, a versatile and wide-area coating method, could be used for the coating and acid treatment of PEDOT:PSS films. Electrical conductivity of the PEDOT:PSS films was significantly enhanced up to $1814 \mathrm{~S} / \mathrm{cm}$ by only one-time surface treatment by a mild acid solution ( $4 \mathrm{M}$ methanesulfonic acid). This is because some PSS chains were removed out from the polymer mixer films without damage on the substrates. UV-vis-NIR spectroscopy, Raman spectroscopy, and cyclic voltammetry were used to characterize the acid-treated transparent conducting films. In this report, obtained transparent conducting PEDOT:PSS films on polyester substrates were used as flexible electrodes for fabrication of flexible electrochromic devices. Poly(3-hexylthiophene) (P3HT) was used as an active layer, which its color changed reversibly from transparent-light blue to purple with a small applied voltage $( \pm 3 \mathrm{~V})$.

\section{Introduction}

Electrochromic devices or "smart windows" can be used in energy-saving windows in the interior of the building. Generally, they are fabricated from materials that their colors can be changed reversibly by electroredox chemical reactions with small applied voltages [1-5]. Nowadays, organic polymeric materials have been interested to fabricate electrochromic devices based on glasses or flexible substrates [6,7]. Conducting polymer is one of the alternatives. A polymer mixer of two ionomers, poly 3,4-ethylenedioxythiophene:poly(styrene sulfonic acid) (PEDOT:PSS), can replace conventionaltransparent-conducting oxide layers as a new transparent conducting electrode for electrochromic devices, because conventional conducting substrates, that is, indium doped tin oxide (ITO) and fluorine doped tin oxide (FTO) have some disadvantages such as high cost, poor mechanical flexibility, and high mechanical brittleness $[8,9]$. Therefore, PEDOT:PSS is chosen as a promising material for flexible electrode applications, due to its advantages, that is, facile coating, high transparency in visible range, and ability of uses in flexible substrates [10-12]. However, the conductivity of conventional PEDOT:PSS films is still low. Various previous works have been reported on improvement of an electrical conductivity of PEDOT:PSS films by adding dimethyl sulfate (DMS), zwitterions, methanol, and amphiphilic fluorocompounds [12-15]. Similarly, addition of $5 \mathrm{wt} \%$ dimethyl sulfoxide (DMSO) or ethylene glycol (EG) into of PEDOT:PSS 
aqueous solution (PH1000) has been reported with an obviously enhanced electrical conductivity up to $600-680 \mathrm{~S} / \mathrm{cm}$ [16-18]. Furthermore, electrical conductivity of PEDOT:PSS (PH1000) films is significantly increased by treatment processes with solutions containing ethylene glycol (EG) and isopropyl (HFIP) alcohol, lithium salt solutions, or phosphoric acid $\left(\mathrm{H}_{3} \mathrm{PO}_{4}\right)[10,19,20]$. Recently, treatment of PEDOT:PSS films by a strong acid (sulfuric acid, $\mathrm{H}_{2} \mathrm{SO}_{4}$ ) solutions has been studied [21,22]. The treatment could increase the conductivity to about $3,065 \mathrm{~S} / \mathrm{cm}$. Nevertheless, the main problems of strong acid treatment are significant damage on PEDOT:PSS films and flexible substrates and high corrosive and dangerous chemicals to environments. To avoid these problems, weak acid such as methanesulfonic acid solution was used to improve the electrical conductivity of these polymer films [23].

For the active layer of organic electrochromic devices, poly (3-hexylthiophene) (P3HT) is an attractive material because its color can be reversibly changed [24, 25]. The polymers films can be fabricated by various techniques, for example, spray coating, spin coating, and doctor blade [26, 27]. Distinctively, convective deposition is one of coating methods that has been utilized to coat polymer to thin films. This method has many advantages, that is, low material and equipment cost, highly repeatable coating, and possibility of upscaling in industries. Furthermore, the one important thing of this technique is about fabrication on large scale substrates coupled with less solution volume [28-30].

The research reported here focused on fabrication of PEDOT:PSS and improvement of the electrical conductivity of PEDOT:PSS films by mild acid (methanesulfonic) treatment with convective deposition. The PEDOT:PSS films were further used as transparent conducting electrodes for flexible electrochromic devices. The $\mathrm{P} 3 \mathrm{HT}$ films and $0.1 \mathrm{M} \mathrm{LiClO}_{4}$ were used as electrochromic active layer and electrolyte solution, respectively. The obtained flexible electrochromic devices were successfully fabricated and characterized.

\section{Experimental}

2.1. Preparation and Treatment of Transparent Conducting Films. In the study of enhancement of electrical conductivity of PEDOT:PSS, rigid glass substrates were used for PEDOT:PSS coating. The glass slides with a dimension of $2.5 \times 2.5 \mathrm{~cm}^{2}$ were cleaned by cleanser, deionized (DI) water, acetone, and isopropyl alcohol (IPA), respectively. After sonication, they were dried in the air. The radio frequency oxygen plasma treatment $(100 \mathrm{~W}, 2 \mathrm{~min})$ was then carried out to increase hydrophilic property of the glasses. Subsequently, PEDOT:PSS (Clevios 1000, $20 \mu \mathrm{L}$ ) was coated on the glasses by convective deposition method at a deposition speed of $3,000 \mu \mathrm{m} / \mathrm{s}$. Then, the coated samples were annealed at $110^{\circ} \mathrm{C}$ on a hot plate for $30 \mathrm{~min}$ in ambient air. Methanesulfonic acid solutions with varying concentrations $(0.5,1,2,4,6$, $8,10,12$, and $15.33 \mathrm{M}$ ) were used for treatment process. The acid solutions were treated on PEDOT:PSS film by convective deposition (one and three times) at a deposition speed of $750 \mu \mathrm{m} / \mathrm{s}$. Afterward, all treated films were annealed at $110^{\circ} \mathrm{C}$

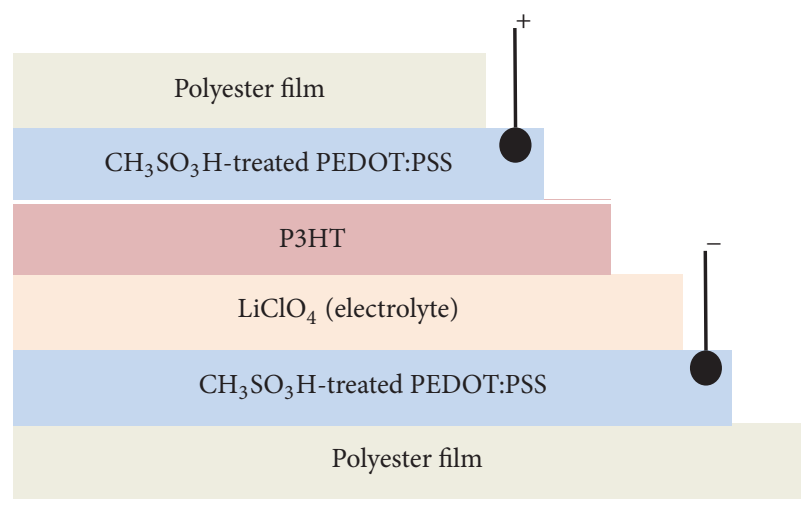

Figure 1: Device structure of flexible electrochromic films.

for $2 \mathrm{~min}$. After waiting for the cooling down (about $5 \mathrm{~min}$ ), isopropanol was used to rinse films and then samples were dried at $110^{\circ} \mathrm{C}$ on a hot plate again.

2.2. Preparation of Flexible Electrochromic Devices. Fabrications and treatments of PEDOT:PSS on flexible substrates (polyester films) were carried out with similar steps compared with that on the glass substrates. P3HT solution $(20 \mu \mathrm{L})$ was then coated on an obtained transparent conducting film by convective deposition at a deposition speed of $1500 \mu \mathrm{m} / \mathrm{s}$. The samples were annealed at $110^{\circ} \mathrm{C}$ for $60 \mathrm{~min}$ in vacuum. Another PEDOT:PSS-coated polyester film was used as a counter electrode of a electrochromic device. Edge of a P3HTcoated PEDOT:PSS/polyester electrode film and edge of a counter electrode film were sealed together by serene sealant. Electrolyte $\left(0.1 \mathrm{M}\right.$ of $\left.\mathrm{LiClO}_{4}\right)$ was ejected into between two electrode films. The structure of flexible electrochromic device is shown in Figure 1. A small voltage of $\pm 3 \mathrm{~V}$ was applied to the device for the color change of P3HT layer.

2.3. Characterizations. The enhanced electrical conductivity of dried polymer films was measured by four-point probe technique (Yokogawa 7561). An UV-vis-NIR spectrometer (AvaLight-DHc Full-range Compact Light Source, Aventes Enlightening Spectroscopy) was used to measure the transmittance spectra of samples. The change conformation of PEDOT chain and some removed PSS chains were observed by Dispersive Raman spectroscopy (NTEGRA, Olympus). Cyclic voltammetry (CV) with operation program (PS Trace 4.6, PlamSens ${ }^{3}$ ) was used to investigate redox reaction and reduction and oxidation states of PEDOT:PSS films and flexible electrochromic devices.

\section{Results and Discussion}

3.1. Fabrication of Transparent Conducting Films and Improvement of Their Electrical Conductivity. PEDOT:PSS nanofilms $(180 \mathrm{~nm})$ were successfully coated on the glass substrates by convective deposition. Electrical conductivity of PEDOT:PSS films was about $1.0 \mathrm{~S} \mathrm{~cm}^{-1}$. Treatment on the surface of PEDOT:PSS films by acid solutions was also successfully carried out by convective deposition. Both strong $\left(\mathrm{H}_{2} \mathrm{SO}_{4}\right.$, 


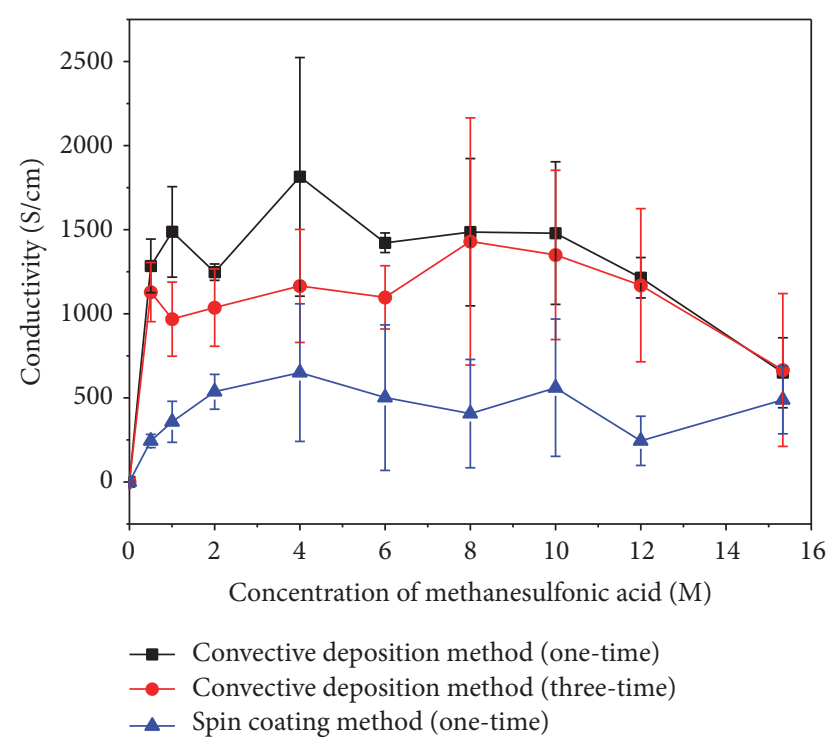

FIGURE 2: Conductivity of PEDOT:PSS films after treatment by methanesulfonic acid at different concentrations of methanesulfonic acid (with different coating methods, thickness of PEDOT:PSS $\approx 80 \mathrm{~nm}$ ).

sulfuric acid) and weak $\left(\mathrm{CH}_{3} \mathrm{SO}_{3} \mathrm{H}\right.$, methanesulfonic acid) solutions were studied to enhance the conductivity of the pristine films. It was found that, in strong acid treatment, the films were peeled off from the substrates (see Fig. S1 in Supplementary Material available online at https://doi.org/10.1155/2017/5176481), because its high acidity can easily destroy the chains of polymer films in both PEDOT and PSS. Not only strong degradation of the PEDOT:PSS films and flexible substrates but also the strong acid can high corrode and damage environments. For methanesulfonic acid-treated films, the optical images of with and without treatment samples showed no difference in morphology and color compared with untreated ones.

In the literature reported on treatment of PEDOT:PSS by spin coating, one- and three-time treatments of weak or strong acid showed the enhancement in the conductivity of the films $[12,23]$. Therefore, in this work, one- or threetime coatings of weak (methanesulfonic) acid solution by convective deposition were carried out. One-time coating by conventional spin coating was also carried out as a reference for comparison. Figure 2 shows electrical conductivities of the acid-treated PEDOT:PSS films. In all cases, convective deposition method not only gave higher conductivity but also spent less amount of solution ( $20 \mu \mathrm{L}$ of methanesulfonic acid solution in one-time coating) than spin coating $(100 \mu \mathrm{L})$, which is an advantage of convective deposition method. Furthermore, convective deposition is possible to upscale an electrochromic for wide area, whereas spin coating can be used use only in the laboratory scale.

It was reported that the conductivity of PEDOT:PSS layers also depends on the concentration of acid solution in the treatment [23]. Therefore, methanesulfonic acid solutions with concentrations in the range of $0.5-15.3 \mathrm{M}$ were used for the treatment in this work. After treatment of samples with increasing concentrations of $0.5-8 \mathrm{M}$, the conductivity of PEDOT:PSS films was found to gradually increase. For further increasing concentration of acid more than $8 \mathrm{M}$, even the conductivity was much higher than pristine films, but the conductivity was found to decrease. This is due to the fact that, at high concentration, the acid solution could degrade PEDOT:PSS film layer. Not similar to the case of spin coating in the literature $[12,23]$, one-time treatment process could improve conductivity greater than three-time one, because three-time treatment may damage the polymer films. Hence, the optimal condition to create transparent conducting layer in this research was one-time treatment with $4 \mathrm{M}$ methanesulfonic acid solution by convective deposition, which resulted in conductivity of $1814 \mathrm{~S} \mathrm{~cm}^{-1}$. The advantages of convective deposition coating method are availability for upscaling thin film coating and use of less sample solution volume compared with the conventional spin coating. The thickness of films can be controllable in nanoscales by the speed in deposition of this technique.

Obviously, the different conductivities of between untreated and methanesulfonic acid-treated films were confirmed and showed significant increase of conductivity from proton transfer by weak acid which has an effect on $\mathrm{PSS}^{-}$of PEDOT:PSS [12, 23], after PSS ${ }^{-}$get $\mathrm{H}^{+}$from acid then formed as PSSH which is neutral. Also, the heat energy from a vibration of polymer chain affected the columbic force between PEDOT $^{+}$(positive charge) and PSS ${ }^{-}$(negative charge) and broke down polymer phases and chains. The coulombic force that occurred was easy to break down because of hydrophobic and hydrophilic properties of PEDOT and PSS, respectively. When thickness of layers of PEDOT:PSS with treatment process increased, the conductivity was found to increase. The relationship between a conductivity of treated PEDOT:PSS films and varied polymer layers is direct variation. Although many layer films gave the high conductivity, it was too translucent to be used in the actual electrochromic application (only 70\% light transmittance, Fig. S2 in Supplementary Material). Hence, this research not only focused on the conductivity but also concerned with the intensity of light pass through the polymer films. From the results, it was found that only 2 layers of treated PEDOT:PSS films (thickness of PEDOT:PSS $\approx 180 \mathrm{~nm}$, light transmittance $>90 \%$ ) were adequately used as transparent conducting layer for electrochromic devices (conductivity $<2000 \mathrm{~S} / \mathrm{cm}$ ).

The obtained transparent conducting layer of PEDOT: PSS films was characterized by UV-vis-NIR spectroscopy as shown in Figure 3(a). The transmittance of the samples without (black line) and with (blue line) treatment by methanesulfonic acid solution was observed. The transmittance in the range of 300-1100 nm of treated films was relatively higher than that of the pristine sample. The improvement of transmittances occurred due to the fact that some PSS chains were removed from the conductive films, leading the structure of PEDOT:PSS films deformed from coil to linear structure $[18,19,21]$. This transmittance is comparable to transparent substrates used for several optoelectrical devices. Therefore, the treated polymer films demonstrated high transmission of light to create transparent-electron conducting layers. 


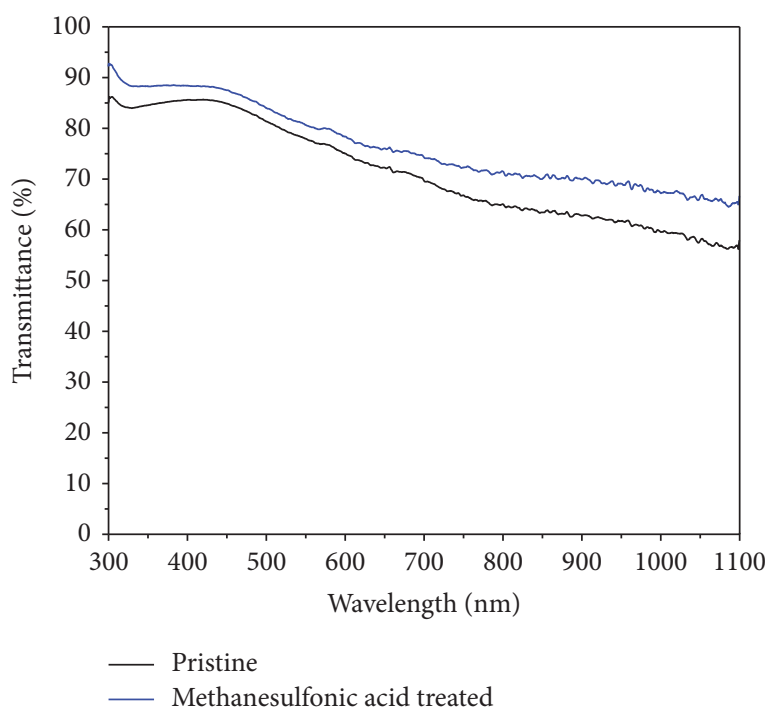

(a)

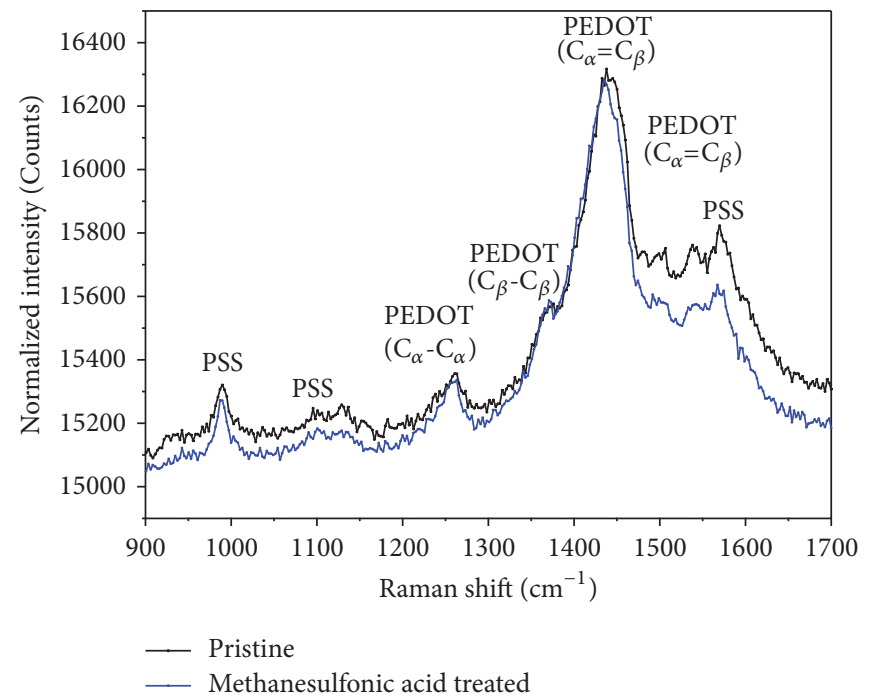

(b)

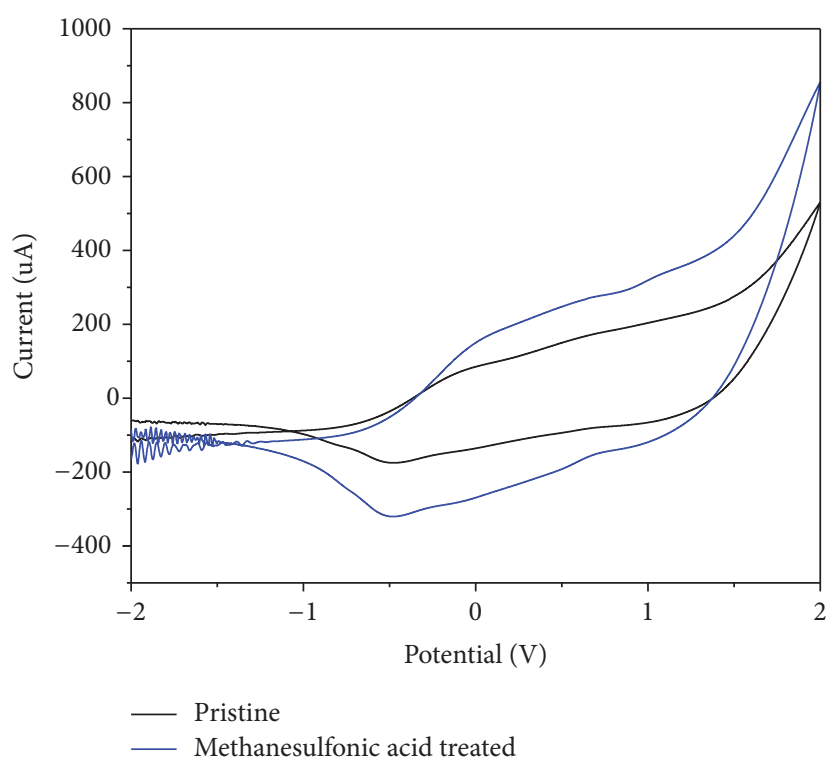

(c)

FIgURE 3: Characterizations of untreated and methanesulfonic acid-treated PEDOT:PSS films on glasses: (a) UV-vis-NIR spectra, (b) Raman spectra, and (c) cyclic voltammogram.

In Figure 3(b), Raman spectroscopy under $532 \mathrm{~nm}$ green light laser excitation provided the results correlated to the effect of acid on PEDOT chain with and without methanesulfonic acid treatment. The vibration mode at 1510, 1450, 1380 , and $1270 \mathrm{~cm}^{-1}$ indicated the position peaks of $\mathrm{C}_{\alpha}=\mathrm{C}_{\beta}$ asymmetrical, $\mathrm{C}_{\alpha}=\mathrm{C}_{\beta}$ symmetrical, $\mathrm{C}_{\beta}-\mathrm{C}_{\beta}$ stretching, and $\mathrm{C}_{\alpha}-\mathrm{C}_{\alpha}$ interring stretching vibration of the five member rings of PEDOT, respectively. Similarly, the characteristic peaks of PSS chains can be specified at the vibration mode of 1000 and $1100 \mathrm{~cm}^{-1}[10,13,31]$. As a consequence, the Ramanfingerprint for treated samples (blue line) demonstrated lower peak intensity of PSS phases than the former (pristine film, black line) which came from acid removed some PSS from polymer films [23]. Thus, this characterization can be also confirmed that PEDOT chain was deformed from benzenoid structure (coil) to quinoid structure (linear or expanded-coil). The Raman peaks at $1450 \mathrm{~cm}^{-1}$ of PEDOT with treatment via acid solution are slightly shifted with respect to one another. In the linear structure, the neighboring thiophene rings in polymer chains are arranged in the same plan. The conjugate $\pi$-electron should be more delocalized than the original structure, responsible for the conductivity improvements $[31,32]$.

Cyclic voltammogram (see Figure 3(c)) revealed the redox behavior of PEDOT:PSS film coated on glasses as a working electrode in $0.1 \mathrm{M} \mathrm{LiClO}_{4}$ aqueous solution with a scan rate $0.05 \mathrm{~V} / \mathrm{s}$. $\mathrm{Ag} / \mathrm{AgCl}$ and $\mathrm{Pt}$ were used as reference and counter electrodes, respectively. Both anodic and cathodic 


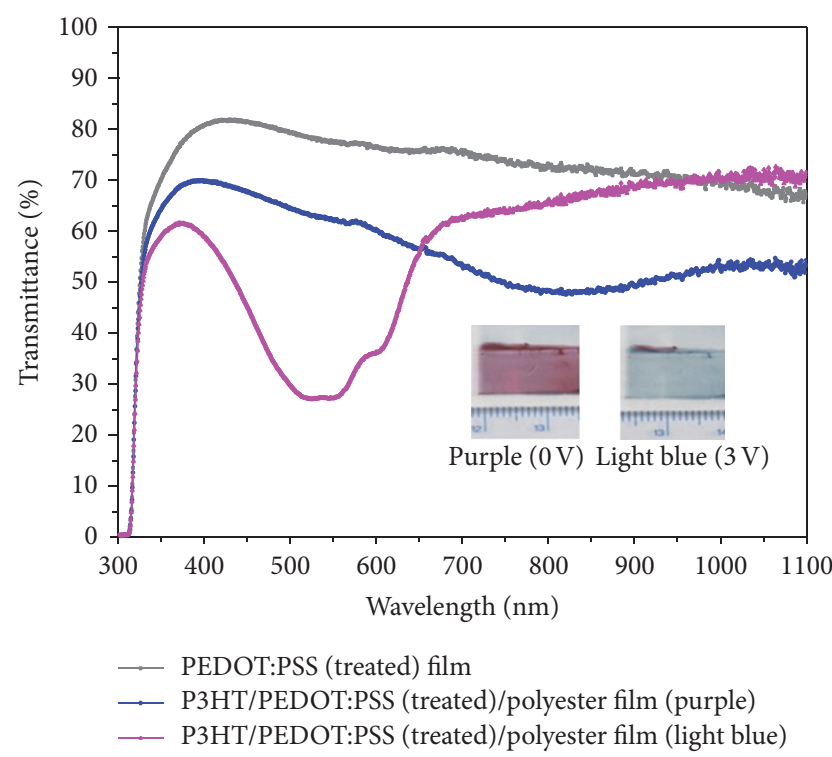

(a)

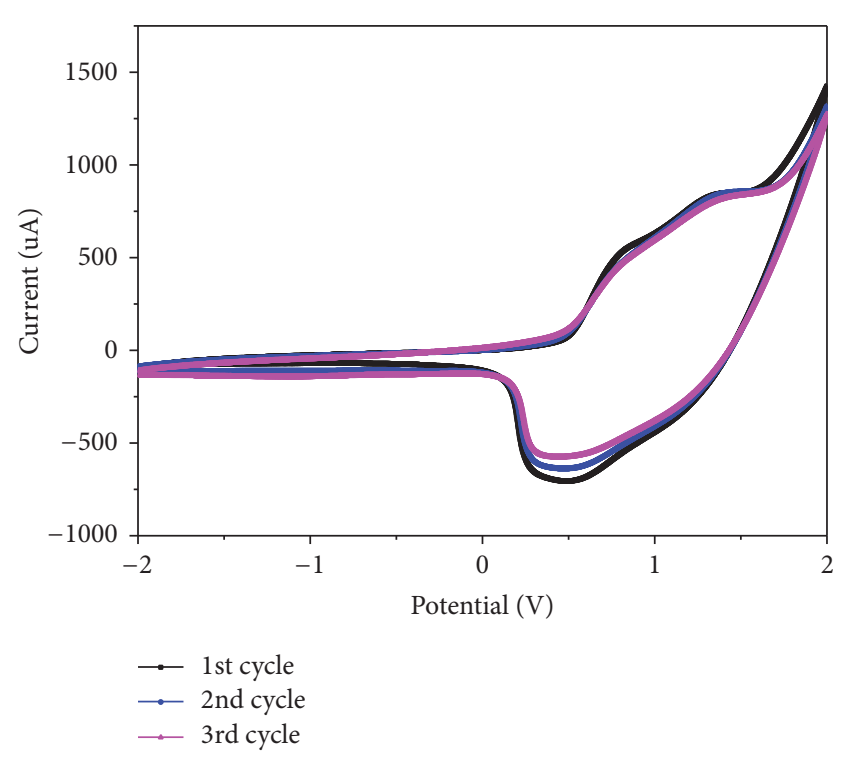

(b)

FIGURE 4: (a) UV-vis-NIR transmittance spectra and (b) cyclic voltammogram of P3HT film coated on PEDOT:PSS (treated)/polyester films anode for electrochromic devices at reduced and oxidized states (applied voltage $=3.0 \mathrm{~V}$ ).

current peaks of pristine PEDOT:PSS films (black line) were less than the treated films (blue lines). Additionally, CV graph also declared that pristine films presented a low electrochemical behavior. Moreover, the color of working electrode made of the pristine PEDOT:PSS films did not change during the test. After treated with weak acid, the electrochemical activity of PEDOT:PSS films significantly increased in the potential range from -2.0 to $+2.0 \mathrm{~V}$. The color of PEDOT:PSS was also significantly changed from light blue to dark blue. The increase in separation of anodic and cathodic peaks implied that the electron self-exchange in polymer films as a result of acid-induce behavior [30], whereas redox process (reduction and oxidation) can be indicated in the potential range of $\mathrm{CV}$ characterization after the methanesulfonic acid treatment. The PEDOT polymer chains were altered from a core-shell structure to a linear or extended-coil structure induced by the weak acid $[23,31,33]$.

3.2. Application of Flexible Electrodes for Electrochromic Devices. The fabrication and treatment conditions obtained from above parts can be used for fabrication of transparent conducting films on flexible substrates. Figure 4(a) represents the transmission of flexible working electrode based on a polyester substrate. Before coating of $\mathrm{P} 3 \mathrm{HT}$, the highest transmittance of treated PEDOT:PSS film (gray line) was $>80 \%$ which was same as a glass substrate. For the samples with $\mathrm{P} 3 \mathrm{HT}$ coating, when the voltage at $3.0 \mathrm{~V}$ was applied, color of $\mathrm{P} 3 \mathrm{HT}$ was changed from purple color to transparent-light blue and change the light transmission properties. The performance of P3HT/ $\mathrm{CH}_{3} \mathrm{SO}_{3} \mathrm{H}$-treated PEDOT:PSS/polyester film as working electrode presented switching responses with bleaching and color times of 3.0 and $5.0 \mathrm{~s}$.
Figure 4(b) shows cyclic voltammogram of P3HT/ $\mathrm{CH}_{3} \mathrm{SO}_{3} \mathrm{H}$-treated PEDOT:PSS/polyester flexible electrode that was recorded in a solution of $0.1 \mathrm{M} \mathrm{LiClO}_{4}$ /acetonitrile (ACN) with $\mathrm{Ag} / \mathrm{AgCl}$ and $\mathrm{Pt}$ as reference and counter electrodes, respectively. The redox peak currents appeared at the range of voltage of -2.0 to $+2.0 \mathrm{~V}$ with a scan rate of $0.02 \mathrm{~V} / \mathrm{s}$. The pristine of P3HT film was in neutral (insulating) state between voltage of -2.0 and $0.0 \mathrm{~V}$. The reversible oxidation/reduction processes were found between 0.0 and $2.0 \mathrm{~V}$. The anodic current showed a peak at $\sim 0.75$ and $1.25 \mathrm{~V}$ where color of P3HT films changed from purple to light blue. The reduction peak current showed at ca. 0.50 and $1.25 \mathrm{~V}$ along with purple color returning. The transition between the bipolaronic and polaronic charge carrier states also observed by these characterizations [24, 25].

From the above results, P3HT film can change color from purple to transparent-light blue in oxidation by penetration of $\mathrm{ClO}_{4}{ }^{-}$ion on its active surface after voltage applied. $\mathrm{ClO}_{4}{ }^{-}$ ions in liquid electrolyte solution not only inserted into the active polymer film but also induced charge transfer into neighboring polymer molecules. The diffusion coefficient values for P3HT film at the oxidation of electrodes are larger than those of the reduction process. So, the redox processes of $\mathrm{P} 3 \mathrm{HT}$ polymer film electrode, which is returned to normal state, associated with the dedoping of $\mathrm{ClO}_{4}{ }^{-}$ions out from polymer chains and took more time to remove because it has a slower switching configuration of P3HT than in the excited state $[25,34,35]$. The performance of P3HT/acidtreated PEDOT:PSS/polyester substrate presented the switching responses with bleaching and color times of 3.0 and $5.0 \mathrm{~s}$ (see Figures 5(a) and 5(b)). All lines of CV cycles were quite overlapped, indicating quite-stable polymer films for color change when the voltage was applied. A few changes in CV cycles from the first cycle were reported as because of swollen 


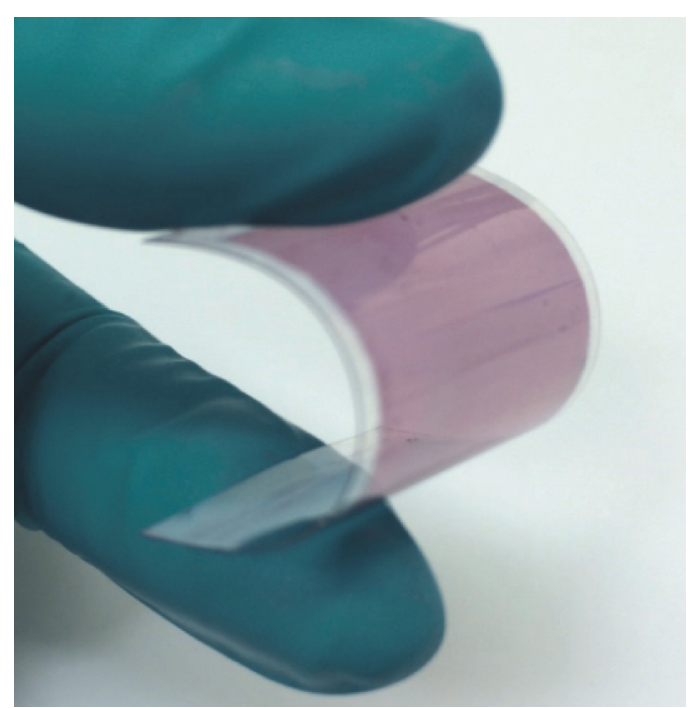

(a)

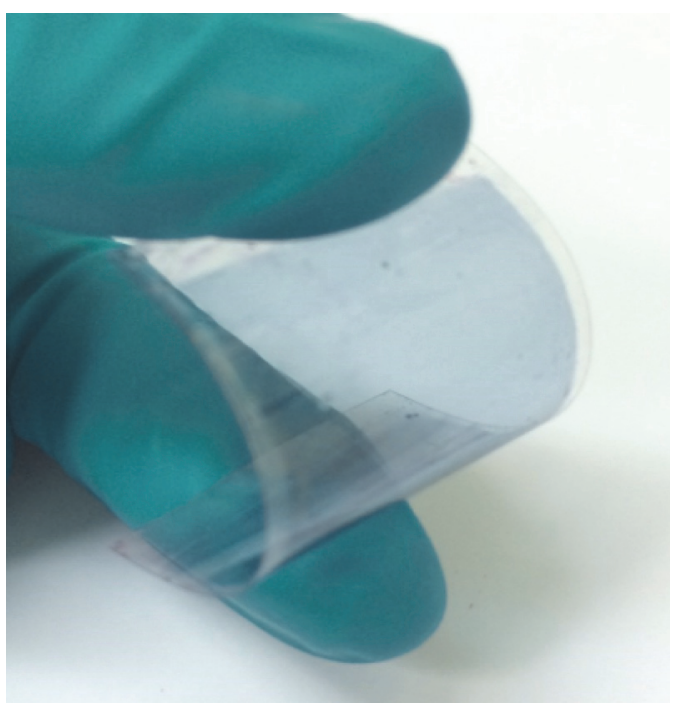

(b)

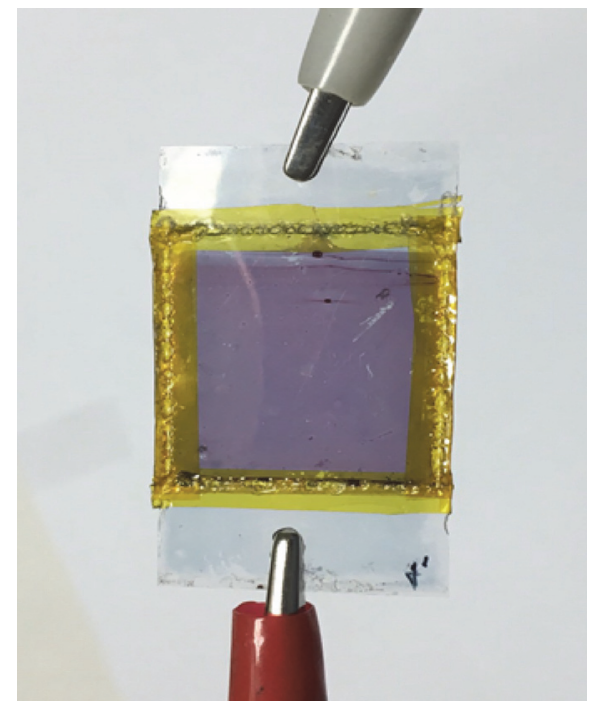

(c)

FIGURE 5: Photo images of P3HT/acid-treated PEDOT:PSS/polyester film at (a) normal and (b) excited states and (c) a prototype of close-film devices.

P3HT films [24, 25]. However, working polymer films can still change colors many times when the voltage was applied. These results indicated that the flexible films in this work are candidates for the development of flexible electrochromic devices. To show feasibility in utilization of flexible films as electrodes for flexible electrochromic devices, a prototype of close-film devices was fabricated and tested as shown in Figure 5(c).

\section{Conclusion}

Electrical conductivity of PEDOT:PSS nanofilms can be enhanced with methanesulfonic acid treatment by only onetime convective deposition coating method. Mild acid is alternative way to improve conductivity better than strong acid solution, because it has no damage on polymer films and plastic substrates. The electrical conductivity of PEDOT:PSS can be enhanced up to $1814 \mathrm{~S} / \mathrm{cm}$ by $4 \mathrm{M}$ methanesulfonic acid solution treatments due to the removal of some PSS chains. Obtained polymer films were created and used as flexible transparent conducting substrates instead of conventional FTO/ITO glasses. Finally, full flexible electrochromic devices were successfully fabricated with the structure of polyester/acid-treated PEDOT:PSS/P3HT/ $\mathrm{LiClO}_{4} /$ acidtreated PEDOT:PSS/polyester. P3HT as active layer can control light and showed high transparency after applying a small voltage $(3.0 \mathrm{~V})$. Switching responses of a bleaching and a color time demonstrated at 3.0 and $5.0 \mathrm{~s}$, respectively. Flexible transparent conducting film showed a potential for 
uses in an actual applications of not only electrochromic devices but also other applications, for example, solar cells and light emitting diodes.

\section{Competing Interests}

The authors declare that there are no competing interests or conflict of interests regarding the publication of this paper.

\section{Acknowledgments}

The authors are sincerely grateful to The Asahi Glass Foundation and The Thailand Research Fund (TRF) (TRG5780129) for providing partial research grants to support this work.

\section{References}

[1] L. L. Fernandes, E. S. Lee, and G. Ward, "Lighting energy savings potential of split-pane electrochromic windows controlled for daylighting with visual comfort," Energy and Buildings, vol. 61, pp. 8-20, 2013.

[2] L. Liang, J. Zhang, Y. Zhou et al., "High-performance flexible electrochromic device based on facile semiconductor-to-metal transition realized by $\mathrm{WO}_{3} \cdot 2 \mathrm{H}_{2} \mathrm{O}$ ultrathin nanosheets," Scientific Reports, vol. 3, article 1936, pp. 1-6, 2013.

[3] Q. Jiang, S. Zhen, D. Mo et al., "Design and synthesis of 9,9dioctyl-9H-fluorene based electrochromic polymers," Journal of Polymer Science, Part A: Polymer Chemistry, vol. 54, no. 3, pp. 325-334, 2016.

[4] Y. He, Y. Xiong, J. Qiu et al., "Preparation and properties of all solid-state electrochromic thermal control thin film," Physics Procedia, vol. 18, pp. 61-65, 2011.

[5] K. A. Gesheva, T. M. Ivanova, and G. Bodurov, "Transition metal oxide films: Technology and "smart Windows" electrochromic device performance," Progress in Organic Coatings, vol. 74, no. 4, pp. 635-639, 2012.

[6] B. Lu, S. Zhen, S. Zhang, J. Xu, and G. Zhao, "Highly stable hybrid selenophene-3,4-ethylenedioxythiophene as electrically conducting and electrochromic polymers," Polymer Chemistry, vol. 5, no. 17, pp. 4896-4908, 2014.

[7] S. Ming, S. Zhen, X. Liu et al., "Chalcogenodiazolo[3,4c]pyridine based donor-acceptor-donor polymers for green and near-infrared electrochromics," Polymer Chemistry, vol. 6, no. 48, pp. 8248-8258, 2015.

[8] O. Inganäs, “Organic photovoltaics: avoiding indium," Nature Photonics, vol. 5, no. 4, pp. 201-202, 2011.

[9] Y. Xia and J. Ouyang, "Significant conductivity enhancement of conductive poly(3,4- ethylenedioxythiophene): poly(styrenesulfonate) films through a treatment with organic carboxylic acids and inorganic acids," ACS Applied Materials \& Interfaces, vol. 2, no. 2, pp. 474-483, 2010.

[10] S. H. Chang, C. Chiang, F. Kao, C. Tien, and C. Wu, "Unraveling the enhanced electrical conductivity of PEDOT: PSS thin films for ITO-free organic photovoltaics," IEEE Photonics Journal, vol. 6, no. 4, pp. 1-7, 2014.

[11] R. J. Mortimer, A. L. Dyer, and J. R. Reynolds, "Electrochromic organic and polymeric materials for display applications," Displays, vol. 27, no. 1, pp. 2-18, 2006.
[12] Y. Xia, K. Sun, and J. Ouyang, "Solution-processed metallic conducting polymer films as transparent electrode of optoelectronic devices," Advanced Materials, vol. 24, no. 18, pp. 24362440, 2012.

[13] M. Reyes-Reyes, I. Cruz-Cruz, and R. López-Sandoval, "Enhancement of the electrical conductivity in PEDOT: PSS films by the addition of dimethyl sulfate," The Journal of Physical Chemistry C, vol. 114, no. 47, pp. 20220-20224, 2010.

[14] Y. Xia, H. Zhang, and J. Ouyang, "Highly conductive PEDOT:PSS films prepared through a treatment with zwitterions and their application in polymer photovoltaic cells," Journal of Materials Chemistry, vol. 20, no. 43, pp. 9740-9747, 2010.

[15] D. Alemu, H.-Y. Wei, K.-C. Ho, and C.-W. Chu, "Highly conductive PEDOT:PSS electrode by simple film treatment with methanol for ITO-free polymer solar cells," Energy \& Environmental Science, vol. 5, no. 11, pp. 9662-9671, 2012.

[16] H. Okuzaki, Y. Harashina, and H. Yan, "Highly conductive PEDOT/PSS microfibers fabricated by wet-spinning and diptreatment in ethylene glycol," European Polymer Journal, vol. 45, no. 1, pp. 256-261, 2009.

[17] P. Wilson, C. Lekakou, and J. F. Watts, "In-plane conduction characterisation and charge transport model of DMSO co-doped, inkjet printed poly(3,4-ethylenedioxythiophene): polystyrene sulfonate (PEDOT:PSS)," Organic Electronics, vol. 14, no. 12, pp. 3277-3285, 2013.

[18] T. Takano, H. Masunaga, A. Fujiwara, H. Okuzaki, and T. Sasaki, "PEDOT nanocrystal in highly conductive PEDOT:PSS polymer films," Macromolecules, vol. 45, no. 9, pp. 3859-3865, 2012.

[19] Z. Zhu, H. Song, J. Xu, C. Liu, Q. Jiang, and H. Shi, "Significant conductivity enhancement of PEDOT:PSS films treated with lithium salt solutions," Journal of Materials Science: Materials in Electronics, vol. 26, no. 1, pp. 429-434, 2014.

[20] W. Meng, R. Ge, Z. Li et al., "Conductivity enhancement of PEDOT:PSS films via phosphoric acid treatment for flexible allplastic solar cells," ACS Applied Materials \& Interfaces, vol. 7, no. 25, pp. 14089-14094, 2015.

[21] Y. Xia and J. Ouyang, "Highly conductive PEDOT:PSS films prepared through a treatment with geminal diols or amphiphilic fluoro compounds," Organic Electronics: physics, materials, applications, vol. 13, no. 10, pp. 1785-1792, 2012.

[22] D. A. Mengistie, C.-H. Chen, K. M. Boopathi, F. W. Pranoto, L.J. Li, and C.-W. Chu, "Enhanced thermoelectric performance of PEDOT:PSS flexible bulky papers by treatment with secondary dopants," ACS Applied Materials \& Interfaces, vol. 7, no. 1, pp. 94-100, 2015.

[23] J. Ouyang, "Solution-processed pedot:pss films with conductivities as indium tin oxide through a treatment with mild and weak organic acids," ACS Applied Materials \& Interfaces, vol. 5, no. 24, pp. 13082-13088, 2013.

[24] J.-H. Huang, C.-Y. Yang, C.-Y. Hsu et al., "Solvent-annealinginduced self-organization of poly(3-hexylthiophene), a highperformance electrochromic material," ACS Applied Materials \& Interfaces, vol. 1, no. 12, pp. 2821-2828, 2009.

[25] Y. Kim, Y. Kim, S. Kim, and E. Kim, "Electrochromic diffraction from nanopatterned poly(3-hexylthiophene)," ACS Nano, vol. 4, no. 9, pp. 5277-5284, 2010.

[26] C. Girotto, B. P. Rand, J. Genoe, and P. Heremans, "Exploring spray coating as a deposition technique for the fabrication of solution-processed solar cells," Solar Energy Materials and Solar Cells, vol. 93, no. 4, pp. 454-458, 2009. 
[27] F. C. Krebs, "Fabrication and processing of polymer solar cells: a review of printing and coating techniques," Solar Energy Materials and Solar Cells, vol. 93, no. 4, pp. 394-412, 2009.

[28] A. L. Weldon, P. Kumnorkaew, B. Wang, X. Cheng, and J. F. Gilchrist, "Fabrication of macroporous polymeric membranes through binary convective deposition," ACS Applied Materials \& Interfaces, vol. 4, no. 9, pp. 4532-4540, 2012.

[29] B. G. Prevo, J. C. Fuller, and O. D. Velev, "Rapid deposition of gold nanoparticle films with controlled thickness and structure by convective assembly," Chemistry of Materials, vol.17, no. 1, pp. 28-35, 2005.

[30] P. Kumnorkaew, Y.-K. Ee, N. Tansu, and J. F. Gilchrist, "Investigation of the deposition of microsphere monolayers for fabrication of microlens arrays," Langmuir, vol. 24, no. 21, pp. 12150-12157, 2008.

[31] J. Ouyang, Q. Xu, C.-W. Chu, Y. Yang, G. Li, and J. Shinar, "On the mechanism of conductivity enhancement in poly $(3,4-$ ethylenedioxythiophene):poly(styrene sulfonate) film through solvent treatment," Polymer, vol. 45, no. 25, pp. 8443-8450, 2004.

[32] A. Keawprajak, W. Koetniyom, P. Piyakulawat, K. Jiramitmongkon, S. Pratontep, and U. Asawapirom, "Effects of tetramethylene sulfone solvent additives on conductivity of PEDOT:PSS film and performance of polymer photovoltaic cells," Organic Electronics: Physics, Materials, Applications, vol. 14, no. 1, pp. 402-410, 2013.

[33] J. Fei, K. G. Lim, and G. T. R. Palmore, "Polymer composite with three electrochromic states," Chemistry of Materials, vol. 20, no. 12, pp. 3832-3839, 2008.

[34] G. Schopf and G. Kossmehl, "Introduction," in PolythiophenesElectrically Conductive Polymers, vol. 129 of Advances in Polymer Science, pp. 3-36, Springer, Berlin, Germany, 1997.

[35] K. Lin, S. Ming, S. Zhen, Y. Zhao, B. Lu, and J. Xu, "Molecular design of DBT/DBF hybrid thiophenes $\pi$-conjugated systems and comparative study of their electropolymerization and optoelectronic properties: from comonomers to electrochromic polymers," Polymer Chemistry, vol. 6, no. 25, pp. 4575-4587, 2015. 

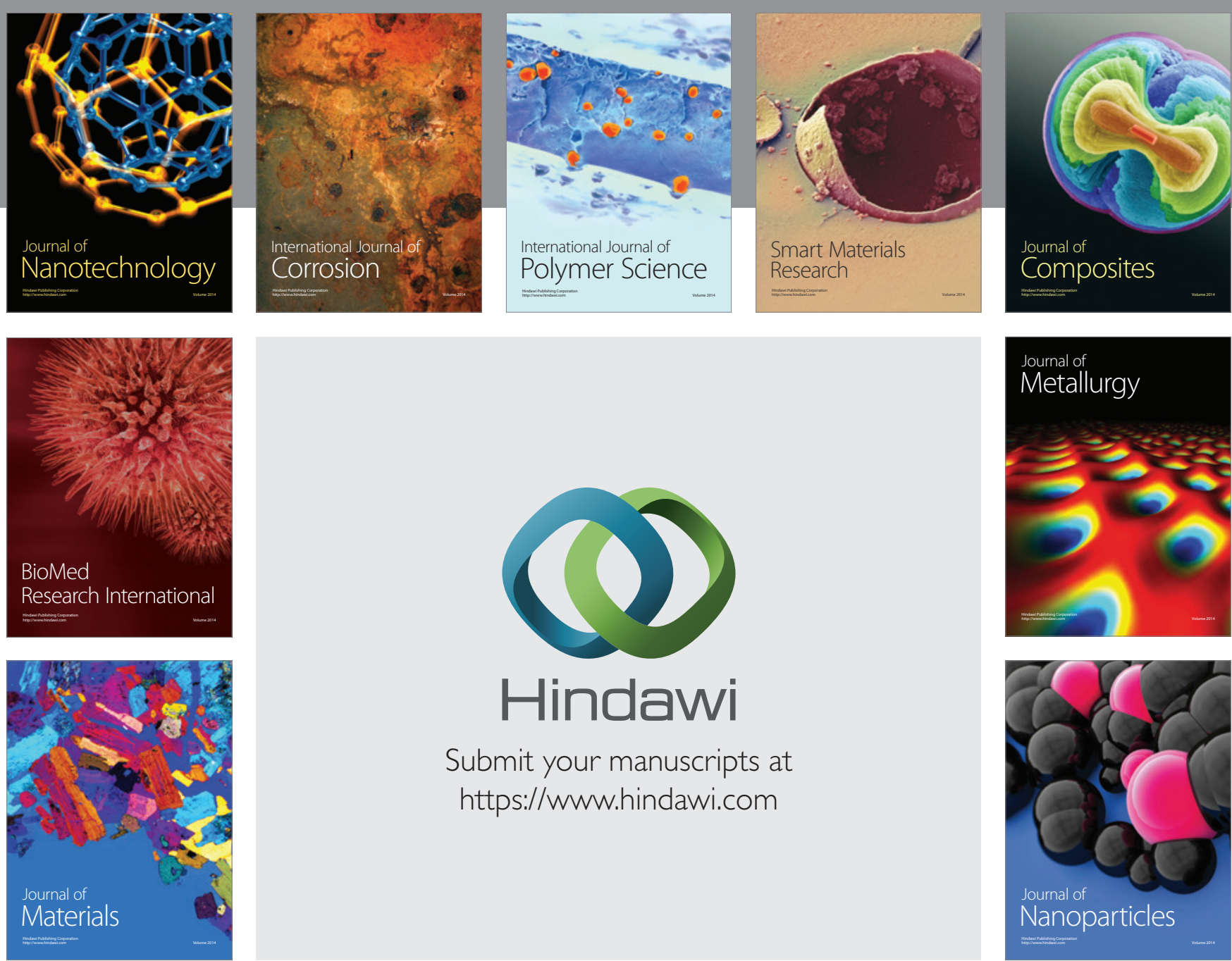

\section{Hindawi}

Submit your manuscripts at

https://www.hindawi.com

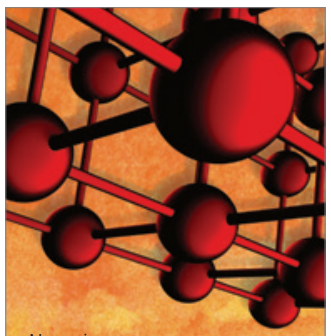

Materials Science and Engineering
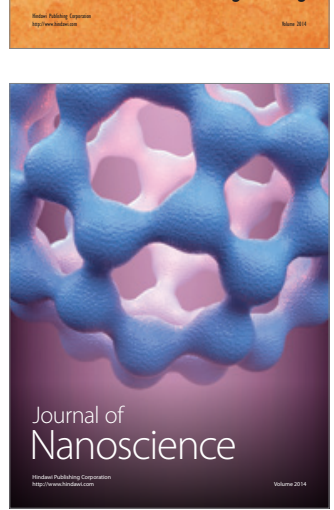
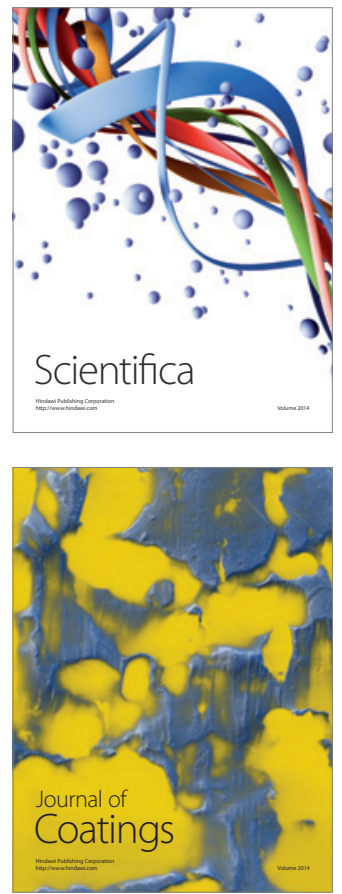
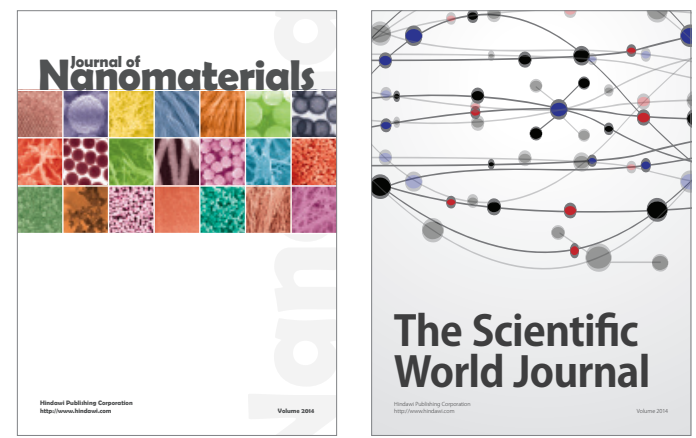

The Scientific World Journal
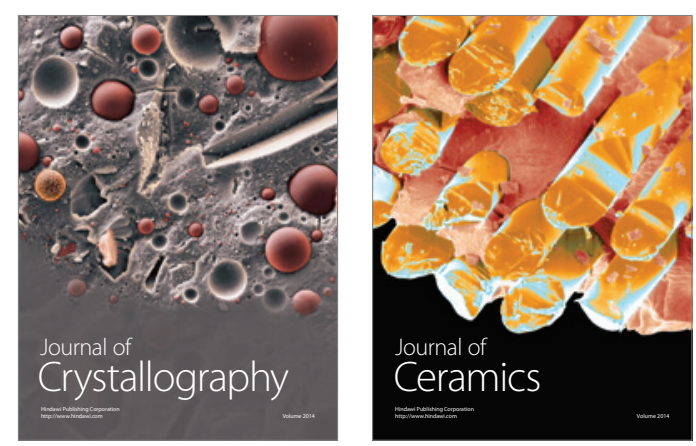
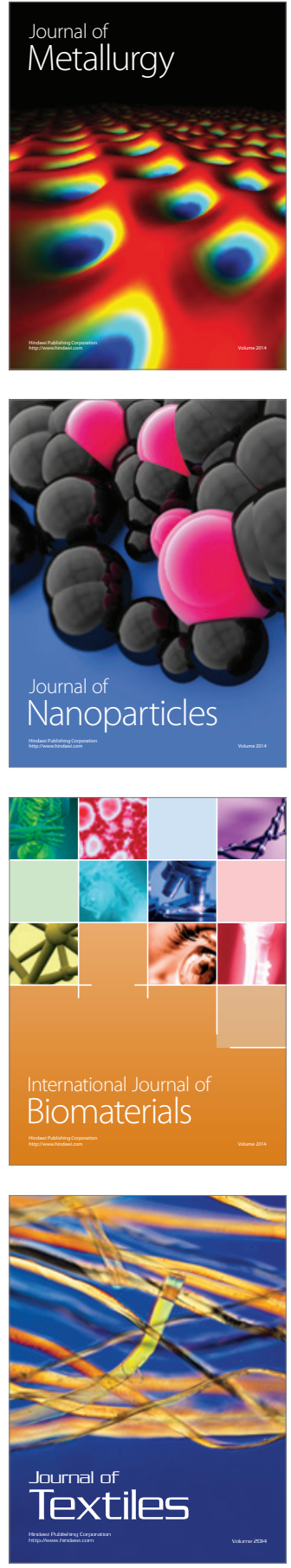